\title{
A Review Of Internet Gateway Discovery Approaches For Mobile Adhoc Networks
}

\author{
Deepak Kumar Patel ${ }^{1}$, Rakesh Kumar ${ }^{2}$ \\ 1Student, M. Tech, CSE Dept., M.M.M. Engg. College, Gorakhpur, UP(273010),India \\ deepakdaring.patel07@gmail.com \\ ${ }^{2}$ Associate Professor, CSE Dept., M.M.M. Engg. College, \\ Gorakhpur, UP (273010),India \\ rkiitr@gmail.com
}

\begin{abstract}
A mobile ad hoc network (MANET) consists of wireless mobile nodes without having a fixed infrastructure. The communication between these mobile nodes is carried out without any centralized control. The communication among the nodes within the infrastructure less networks is done through some routing protocol. But whenever any mobile node want to communicate a node in a network that is outside the ad hoc network such as internet, there should be an appropriate mechanism for establishing this connection. Gateway discovery is a fundamental process in connecting MANET with the internet. A mobile node can connect to the internet by discovery of some specialized nodes called as gateway nodes These Gateway nodes act as a bridge between the mobile ad hoc networks and the internet. The basic aim of the gateway discovery approach is to modify the route discovery process so that it is not only used for discovery of destination mobile nodes but also the gateways. In this paper we are going to present a review of various gateway discovery approaches which are used for establishing the interconnection of mobile ad hoc networks and internet.
\end{abstract}

\section{Keywords}

MANET, Gateway, Mobile IP, DAD, Address Auto-configuration, Gateway Forwarding, Handoff, Gateway Discovery, Gateway Selection.

\section{INTRODUCTION}

A mobile ad hoc network [1] is organized as the collection of various mobile nodes. It is formed spontaneously in the areas where establishing an infrastructure network causes delay in the work as well as enhances the cost. These areas include flooded areas, earthquake affected areas, etc. As the nodes are mobile there is not any fixed infrastructure of MANET. The mobile ad hoc network is composed of portable nodes, notebooks and palmtops. This portability brings a significant issue of mobility. This is a key challenge in ad-hoc networks. The nodes in the mobile ad hoc networks are constrained to use limited resources. They have low battery power, limited user interface and low quality display. The nodes in the mobile ad hoc networks can communicate with one-another through the use of some routing protocol which decides which way to route the information from source to destination. This communication among the mobile nodes occurs for retrieving the essential information they need. When a mobile node wants any information outside the mobile ad hoc network in which they are present, they have to use some mechanism other than routing protocol. The communication between mobile ad hoc networks and the internet occurs through some special approach called as gateway discovery. The gateway [2] acts as an interface between the mobile ad hoc network and the internet. As the nodes are mobile the topology of the MANET changes frequently. Therefore managing permanent connection to the internet is a critical issue in mobile ad hoc networks. Gateway eliminates this difficulty by taking over all the communication between MANET nodes and the internet. All the incoming and outgoing traffic between the MANET and internet passes through the gateway that forwards it to the appropriate destination. Different mechanisms have been proposed to integrate MANETs and the Internet. The communication between MANET and internet is shown in figure1. 


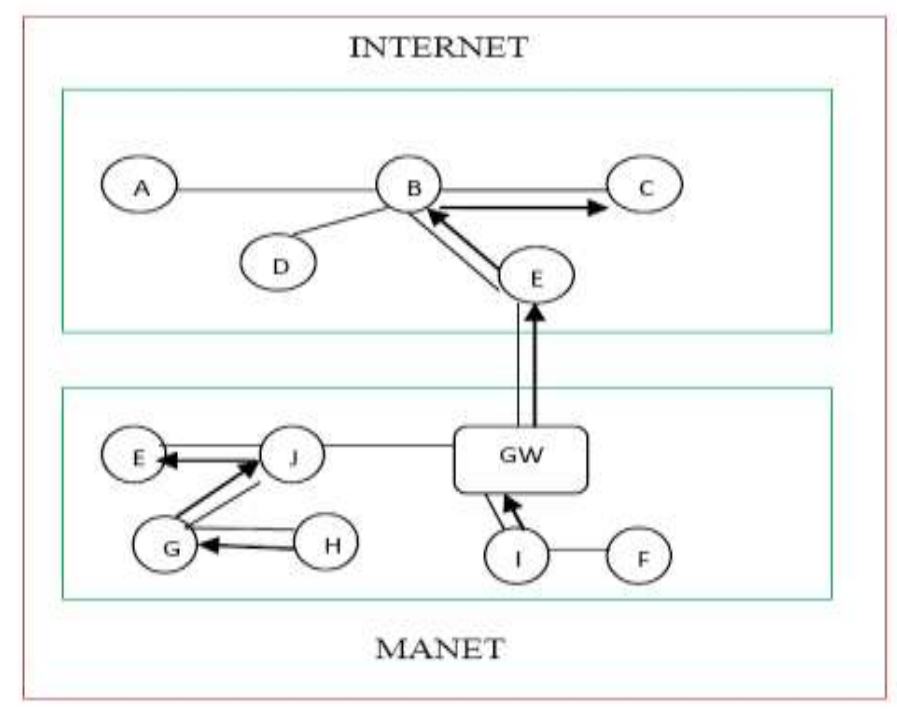

Fig 1: Integration of MANET with Internet

The Figure shows two networks. One is the mobile ad hoc network and the other one is the internet. The communication among the mobile nodes is easier and the nodes can communicate directly, while the communication between mobile node and an internet server is through the gateway only.

The paper is organized as following. Section 2 presents fundamentals of internet gateway discovery. Section 3 gives the classification of internet gateway discovery approaches. Current proposals on various internet gateway discovery schemes is discussed in section 4. A tabular comparison of these proposals is given in section 5 . The conclusion and future scope of the paper is given in section 6.Various latest trends of research on internet gateway discovery is presented in section 7.Finally section 8 contains the organization of the references used in the paper.

\section{INTERNET GATEWAY DISCOVERY FUNDAMENTALS}

Gateway Discovery is a method [29] which allows a MANET node to discover an IGW [21] to which traffic for the Internet can be delivered, and from which traffic returned from the internet can be received. The different discovery mechanisms can be classified into three sub-classes: proactive, reactive, or hybrid. In the proactive approach [22], each IGW broadcasts periodically an advertisement, while in the reactive approach a MANET node sends a solicitation and waits for a reply from the IGW. Proactive approach requires much traffic overhead on the MANET, while the reactive approach [23] causes higher delay. The hybrid approach [24] compromises with the balance, in which each IGW periodically broadcasts the advertisement within the radius of n-hops. MANET nodes that are located further than n-hops away from the IGW, must use the reactive approach to discover the IGW. One more gateway discovery approach which is days is adaptive gateway discovery which dynamically adapts itself.

being used now a parameters which are as following.

Shortest hop count [30] is the number of intermediate hops from the node to the gateway.

Load-balancing [31] is used for MANET nodes within the same MANET domain to send intra MANET traffic to choose different immediate node to destination while for inter-MANET traffic, choosing different IGWs for forwarding traffic from MANET to Internet and vice versa

Euclidean distance [32] is the spatial distance between the MANET node and the IGW.

\subsection{Address Auto-Configuration}

One of the requirement of MANET is to support IP services and the IP traffic routing with the Internet. So for this purpose MANET address space based on IPv4/IPv6 is required. Once a mobile node has chosen one gateway, every traffic sent through this gateway to the internet need a source address with the same prefix as the Gateway. Moreover, the MANET addressing schemes must be auto-configured [25] and distributed to support for the self-organized and dynamic characteristics of MANETs. Ad hoc hosts require an address auto-configuration mechanism in order to configure a globally routable address instead of alternatives such as Network Address Translation (NAT).There are various addressing schemes for MANETs based on IP address auto configuration [26].They can be categorized into two classes. One is conflict detection allocation [27] and other one is conflict-free allocation [28].

Conflict-detection allocation mechanisms requires to choose an IP address from a set of available addresses, configuring it as temporary address and asking the rest of the nodes of the network to verify the address uniqueness and requesting for approval from all the nodes of the network. If there is an address conflict, the address has been already configured by another node and the node should pick a new address and repeat the method. This process is called duplicate address detection (DAD). 
Conflict-free allocation mechanisms, on the other hand, assume that the addresses are delegated uniquely, and that they are therefore not being used by any other node in the network. This can be acquired by ensuring that the nodes, which allocate the addresses, have disjointed address pool. So here the DAD procedure is not required.

\subsection{Protocol Stack}

Whenever any node in the MANET wants to send the traffic towards an internet node then it must be transmitted via the gateway. So the gateway has to translate between these two different protocols and must understand both. Therefore, it needs to implement both the MANET protocol stack and the TCP/IP suite [22]. The protocol stack for the MANETINTERNET integration is as following.

\section{MANET} NODE

\begin{tabular}{|c|c|}
\hline \multicolumn{2}{|c|}{ Application } \\
\hline \multicolumn{2}{|c|}{ UDP } \\
\hline IP & AODV \\
\hline LLC 802.11 \\
MAC
\end{tabular}

GATEWAY

\begin{tabular}{|c|c|c|}
\hline \multicolumn{2}{|c|}{ Application } & Application \\
\hline \multicolumn{2}{|c|}{ UDP } & UDP \\
\hline IP & AODV & IP \\
\hline $\begin{array}{c}\text { LLC 802.11 } \\
\text { MAC }\end{array}$ & Data link \\
\hline \begin{tabular}{c} 
802.11 PHY \\
\hline
\end{tabular} & Physical \\
\hline
\end{tabular}

HOST

\begin{tabular}{|c|}
\hline Application \\
\hline UDP \\
\hline IP \\
\hline Data link \\
\hline Physical \\
\hline
\end{tabular}

Fig 2: Protocol architecture for interconnection between mobile ad hoc network and internet Host.

\subsection{Gateway Forwarding}

Internet gateway forwarding [33] is used to forward traffic within the MANET, out of the MANET to the Internet, or from the Internet to the MANET. It can be categorized into inter-MANET and intra-MANET forwarding strategies. The inter-MANET forwarding strategies uses two main methods, default routes and tunneling.

Default routes [34] are used by the default next-hop to send packets to those nodes which do not have any explicit entry in their routing table. Usually, the default route is used to forwards packets towards an IGW, where packets are further forwarded towards the destination in the Internet.

Tunneling [35] is the IP-in-IP encapsulation technique which is used to get traffic into and out of the MANET. The outer IP header is for the tunneling connection between the source MANET node and the IGW, while the inner IP header is for the connection between the source MANET node and the destination.

\subsection{Handoff In Manet-Internet Connectivity}

A node performs a handoff if it changes its IGW while communicating with a correspondent node (CN) in the Internet [36]. In conventional mobile networks, e.g., WLANs, the quality of the wireless link between a mobile node and the neighboring access points (APs) determines to perform handoff from one AP to another. The performance of these types of handoffs depends on the mobility management protocol in the access network. In MANETs, on the other hand the situation is quite complex because some of the nodes do not have a direct wireless link to an AP, but they are connected via other intermediate nodes. Thus, they cannot initiate handoffs that are based on the link quality to the AP. Rather, the complete multi-hop path to the AP, which serves the current IGW, must be taken into consideration. A handoff can occur only if an ad-hoc node itself or any intermediate ad hoc node moves and breaks the active path. In general, if the path between an ad-hoc node and the IGW breaks and there is no other path to the same IGW, the ad-hoc node has to perform IGW discovery to establish a new path to another IGW.

Multi-hop handoff schemes can be classified into forced handoff and route optimization-based hand off [37].Forced handoff occurs when the path between the source or destination mobile node and the IGW is during data transmission due to the movement of the MANET node. So, a new path to the internet has to be set up. Route optimization-based hand-off is a handoff that results from route optimization. If the source or target MANET node observes that a shorter path to the internet becomes available while communicating with a corresponding node, the active path will be optimized. In case the shorter path goes via a different IGW, a route optimization-based handoff occurs.

\section{TAXONOMY OF GATEWAY DIS-COVERY APPROACHES}

There have been several approaches for gateway discovery. One such classification is given as following [3]. 


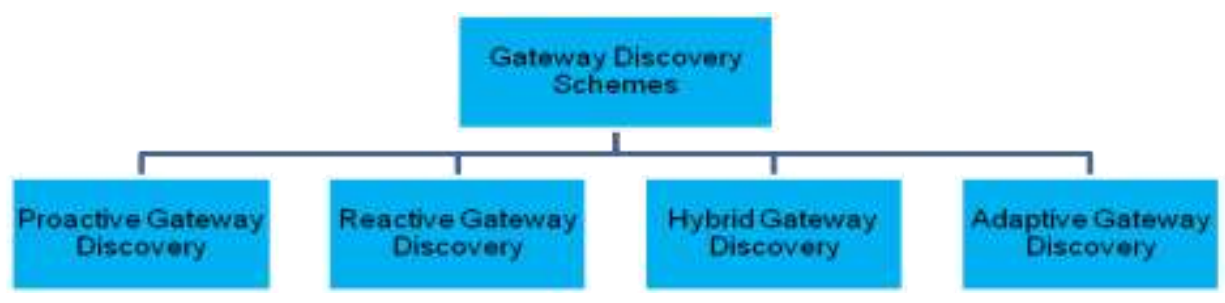

Fig 3: Classification of gateway discovery schemes.

\subsection{Proactive Gateway Discovery Scheme}

This scheme [4] makes use of a special message called as gateway advertisement [5]. The Gateway discovery is initiated by the gateway itself. The Gateway broadcasts a gateway advertisement message which is rebroadcasted after a certain time interval called as advertisement interval. The time between two intervals is chosen in such a way that the network is not overwhelmed by the traffic. The nodes which are in the range of the gateway receive the advertisement message. On receiving the message the nodes which don't have route to gateway create a route entry for it in their routing table. Those nodes which have a route to gateway update their routing information.

\subsection{Reactive Gateway Discovery Scheme}

In reactive gateway discovery [9] scheme the nodes demand route to the gateway reactively. Whenever any node wants to fetch some information from the internet, it broadcasts a Route Request message (RREQ) to the IP address of a group of all gateways in the mobile ad hoc networks using ALL_MANET_GW_MULTICAST address. This message is received and replied only by the gateways. The intermediate nodes do not to reply to this message on receiving such message they just rebroadcast them. The advantage of this approach is that control messages are generated only when a mobile node needs information about reachable gateways. On receiving RREQ message gateways reply source node with the corresponding route reply (RREP) messages by uni-casting them. After that mobile nodes can access the internet easily as the connection has been established.

\subsection{Hybrid Gateway Discovery Scheme}

The hybrid gateway discovery scheme [13] is the combination of both proactive and the reactive approaches. Firstly the gateway broadcasts the Gateway Advertisement message proactively to an area confined to a limited number of hops which is called as the TTL value of the message. The TTL is set to advertisement zone so that the advertisement message can be forwarded only up to this maximal number of hops through the ad hoc network. This area is called as the proactive zone. The nodes that are outside the proactive zone establish connection to the gateway reactively. The format of gateway advertisement message is as following.

\begin{tabular}{|c|c|c|c|}
\hline TYPE & RESERVED & PREFEX SZ & HOP COUNI \\
\hline \multicolumn{4}{|c|}{ RREQ D } \\
\hline \multicolumn{4}{|c|}{ DESTINATION IP ADDRESS } \\
\hline \multicolumn{4}{|c|}{ DESTINATION SEQUENCE NUMBER } \\
\hline \multicolumn{4}{|c|}{ ORIGINATOR IP ADDRESS } \\
\hline
\end{tabular}

Fig 4: Gateway Advertisement message format

\subsection{Adaptive Gateway Discovery Scheme}

Information is easily provided by the gateway only if it is routing those data grams that it would receive anyway. Adaptive gateway discovery algorithm is based on this idea. In this approach number of hops of its active source location is maintained.

\section{CURRENT PROPOSALS}

In this section we present a summary of various gateway discovery proposals which have been proposed by various researchers. 


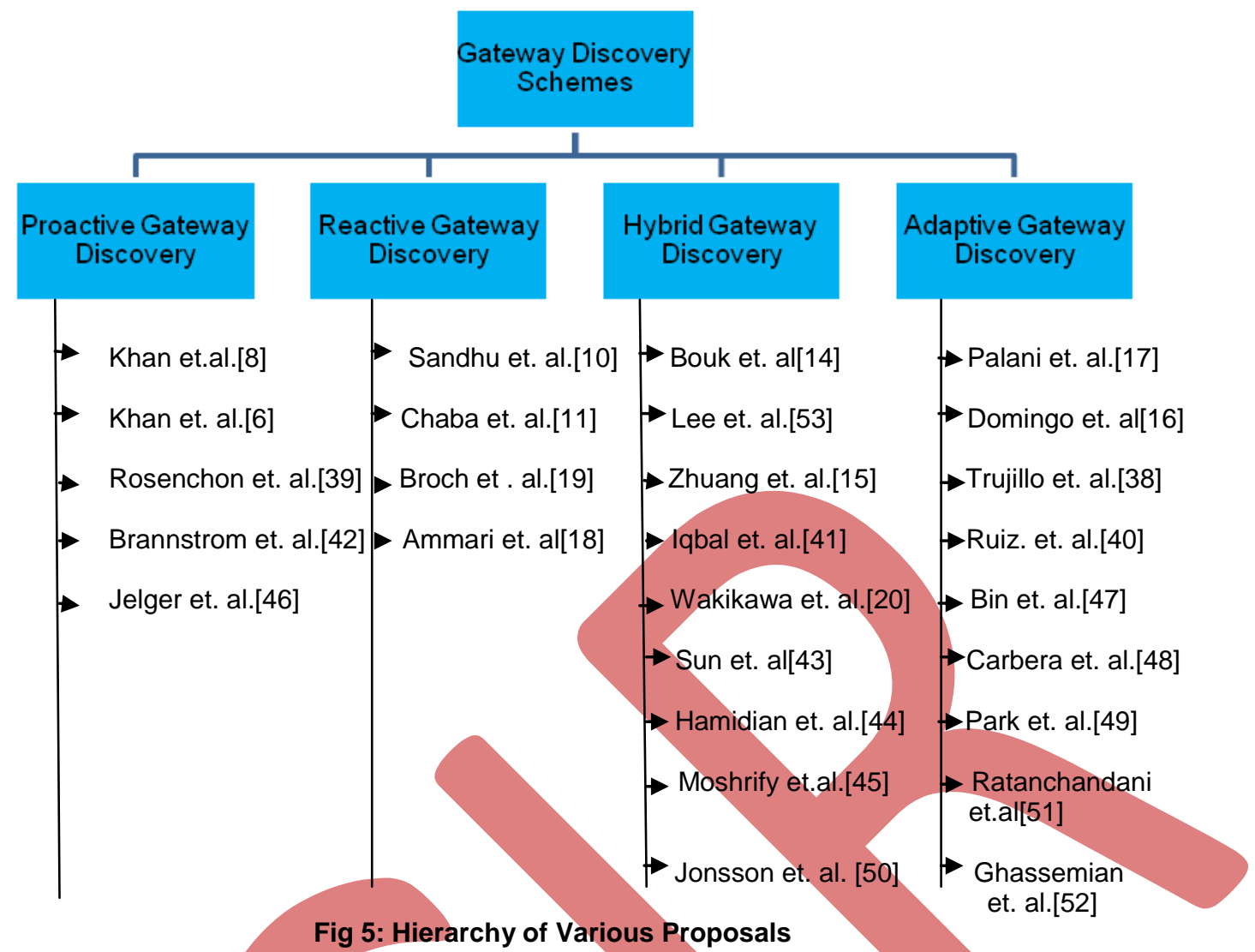

Khaleel Ur Rahman Khan et al. [8] proposed a protocol in which each mobile host maintains a routing table that stores the number of hops, and the sequence number for all the destinations. The routing table updates may be timedriven or event-driven. The interval between the two updates is known as the periodic route update interval. In DSDV the low packet delivery ratio is because of usage of stale routes due to broken links. The existence of stale route does not imply that there is no valid path to the destination. The packets can be forwarded through other neighbors who may have routes to the destination. When an intermediate link from the host say ' $S$ ' to the destination say 'D' breaks, the Effective DSDV protocol creates a temporary link through a neighbor which has a valid route to the desired destination. The temporary link is created by sending one hop ROUTE-REQUEST and ROUTE-ACK messages..

In this section we briefly describe the scheme of K.Palani et al. [17] based on the maximal source coverage algorithm. Initially, the gateways do not send control advertisements (GC REP) periodically. When a node needs a route to the Internet, it issues a GC REQ message which is flooded throughout the network. The gateways present in the MANET receive the GC REQ and send a GC REP message in unicast to the originator. It contains the subnet prefix which is later on used by the node to auto-configure its global IP address. Reverse routes to the node are created as the GC REQ message is being forwarded, and routes to the gateway when the GC REP is sent back. So, the ad hoc node can start sending data traffic to the internet after configuring its global address. Data packets addressed to nodes in the internet pass through a gateway. Thus, it can collect the number of hops from itself to every source. The TTL of the GC REP messages which are periodically flooded is set to the distance to the farthest source. The motivation behind this is that active sources are covered by the proactive sending of control messages, and therefore we can avoid the reactive route discovery when the route to the Internet is lost, which is very expensive in terms of control overhead.

Khaleel Ur Rahman Khan, et. al.[6] proposed eDSDV or extended DSDV protocol which is based on dynamic buffer management strategy instead of the fixed size buffer technique. With this approach the chances of discarding the packets are very low. In case of broken links the RREQ packets are broadcasted with a hop count of two rather than one. Performance of the conventional DSDV algorithm fades because of increase in the network size and the rates of mobility. This algorithm improves various performance metrics of the DSDV protocol such as packet delivery ratio, end-to-end delay and the number of dropped packets. When a next hop link from the source to the destination breaks, the proposed protocol creates a provisional link through a neighbor which has a valid route to the desired destination[7]. The provisional link is created by sending two hop route-request and route-acknowledgement messages. This mechanism is explained in figure 5 .

Harpreet Kaur Sandhu et al. [10] proposed AODV+, an enhanced version of the AODV protocol. In the traditional AODV protocol the mobile node initiates the route discovery process by broadcasting the route request message (RREQ) with its own IP address as the source IP address and destination IP address of an internet host. When an intermediate node receives the RREQ packet, it searches its routing table for a route on the way to the destination i.e. the internet host. 
If there is no route, the intermediate node updates its routing table and found, rebroadcasts the RREQ messages. If the route is according to AODV the intermediate node would send RREP back to the source of RREQ. The source thinks that the destination is a mobile node that can be accomplished via the intermediate node. It is significant for the source node to know that the destination is an internet host and not a mobile node because they are processed in a different way. This shortcoming of AODV was removed in AODV+. It prevents an intermediate node to send back RREP to the source of the RREQ. If the destination is an internet host instead, the intermediate node updates its routing table and rebroadcasts the received $R R E Q$ message.

Yogesh Chaba et al. proposed a gateway selection protocol that is used for hybrid MANETS. The multipath extension [11] is useful because if one of the path fails the data can be routed through another path .It consists of two phases. One is the request phase and the other one is the reply phase. In request phase the source node broadcasts a route request (RREQ) packet to its neighbors and it is broadcasted until it reaches for the destined node. In the Reply phase the route reply (RREP) is sent to the source by the destination. This way the route cutoff problem is solved.

In MANET, nodes move at random speed and direction that result in a dynamic topology. Safdar Hussain Bouk et. al.[14] proposed a gateway discovery scheme in which movement of each node is considered as a sequence of random length intervals called epochs during which a node moves in a direction $\theta$ at a constant speed v. In this situation the link availability period between two nodes is varying at different time intervals and the path availability period between two nodes that are not immediate neighbors of each other, is equal to the minimum link availability period between intermediate nodes in that path. Li represents the minimum link availability period and lu is the link availability period between two neighboring intermediate nodes in a path from a source MANET node (S) to the gateway node and $\mathrm{Li}=\min \{l \mathrm{u}\}$. Almost all protocols just compute the traffic load of a gateway node and based on that information they select gateway. The residual load capacity of a path is the minimum available load capacity at any node, including intermediate nodes and the gateway node, in that path. The overall residual load capacity $\mathrm{Cl}$ of path $\mathrm{i}$ is computed as $\mathrm{Ci}=\min \{\mathrm{c}\}\}$ where cj denotes the residual capacity of the intermediate nodes in the route including gateway node. Latency is the propagation delay plus processing time of a packet from one node to another node.

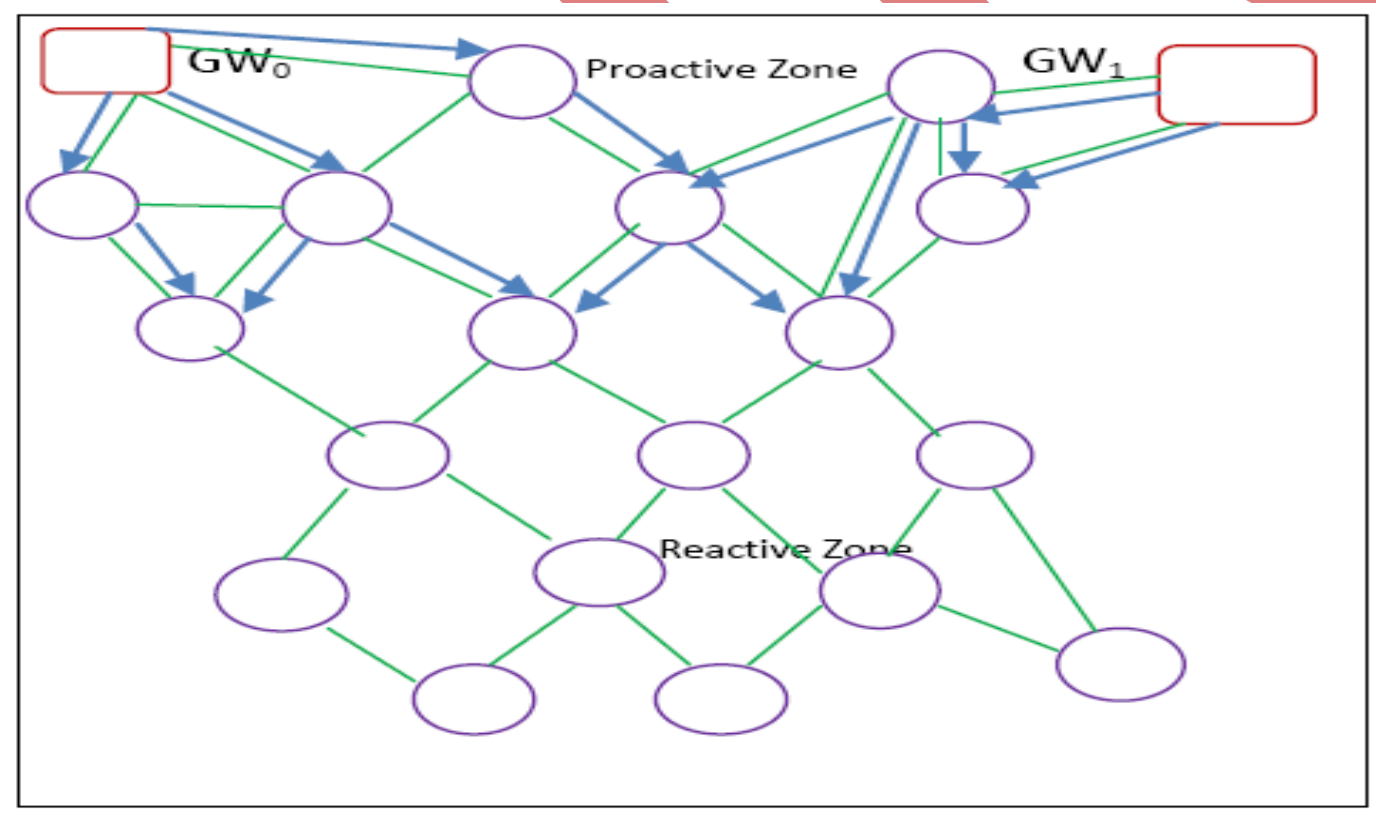

Fig 6: Zone Division in Hybrid MANET

The figure indicates that zone is divided through the propagation of gateway advertisement (GWADV) messages.

Lee et al. [53] proposed a hybrid gateway discovery protocol that requires a source routing protocol in the Ad Hoc network. A gateway sends out new advertisements only when it detects any topology change in the Ad Hoc network. Moreover, advertisements are only forwarded to nodes that are either connected to the Internet or that have actually moved. Advertisements are only generated if the ratio between the number of Internet joining nodes and the number of advertisement forwarding nodes exceeds a threshold. The traditional advertisements are broadcasted with a relatively long time interval. They rely on a source based routing protocol, that obstructs the application to particular type of routing protocol.

Lin Zhuang et al. [15] proposed a hybrid gateway discovery approach. An Internet gateway periodically broadcasts a GWADV. The nodes that receive GWADV create or update reverse route entries for the IGW and maintain such routes as default entries in their routing tables. MNs that cannot receive GWADV issue Route Request for IGW packets (RREQ_l) to discover gateway reactively. To avoid unidirectional links and meanwhile to relieve broadcast storm, $500 \mid \mathrm{P}$ a g e 
Shen improves the original hybrid gateway discovery scheme by extending AODV hello messages with local connectivity information. Each MN maintains a Neighbor Node List (NNL) to record its set of neighbors (i.e., all nodes from which it can hear hello message) and it then appends this set in its coming HELLOs. When a node receives a hello message from a neighbor, it will add it into

its NNL and if it is not present in the neighbors set in this hello message, the node can conclude that it is the sink of a unidirectional link between them and mark this neighbor as asymmetric neighbor in NNL. Otherwise the neighbor will be marked as symmetric neighbor.

Wakikawa et al. [20] proposed an approach to global Internet connectivity over the IPv6 MANET environment, where mobile nodes in the Ad Hoc network are configured with new globally routable IP addresses based on the neighbor discovery protocol (NDP) of IPv6. The gateway advertisement message contains the global IPv6 address of the gateway, the network prefix advertised by the gateway, the prefix length and the life time associated with this information. They specify a stateless auto-configuration mechanism, which is based on network prefixes advertised by Internet gateways. The nodes concatenate an interface identifier to one of those prefixes in order to generate the IP address.

Mari Carmen Domingo et al.[16] proposed an adaptive gateway discovery approach that has been mainly designed to reduce congestion problems in an ad hoc network and that helps real-time applications to maintain their QoS parameters even in the presence of high traffic. This approach defines a transmission range where the gateways periodically send advertisement messages and they are propagated around a limited zone (a certain number of hops away from the gateway). If a mobile node wants Internet connectivity and it is outside the gateways transmission range and the propagation zone of the gateways advertisements, it should broadcast a message to the group of gateways in the ad hoc network. The gateways should respond sending back a reply and the routing protocol of the mobile node selects the reply of the gateway which offers the best route towards internet in terms of number of hops accordingly to the normal functioning of the AODV routing protocol.

Broch et al. [19] proposed a solution for the integration of MANET with Mobile IP using a source routing protocol. It contains a border router, which has two interfaces. The communication within the ad hoc network is done through the DSR protocol. While its interface connected to the Internet is configured to use normal IP routing mechanisms. Mobile nodes in an Ad Hoc network are assigned home addresses from a single network. The nodes within range of the foreign agent act as gateways between the Ad Hoc network and the Internet. As a reactive approach, foreign agent discovery is only done when required. Traditional IP routing is used on the Internet side while within MANET DSR protocol is used. Foreign agents are responsible for connecting the Ad Hoc network with the Internet.

In [38] F. D. Trujillo et al. proposed an adaptive gateway discovery scheme. In the proposals of proactive gateway discovery schemes, the interval of emission of MRA messages (Modified Router Advertisement) is fixed to a constant value T. This interval is dynamically configured in this approach. The optimal value of $\mathrm{T}$ depends on the network conditions such as the load, the node mobility, the number of traffic sources. Here, the gateway adjusts the $T$ taking into account the number of received MRA messages which are retransmitted by the gateway's neighbors. When the gateway receives various MRA messages from its, it means that all these nodes have updated the routing entry to the gateway accordingly. Additionally, when the number of neighbors is high, we may assume that most routes to external hosts are composed of few number of hops. It causes the routes to have a longer lifetime .In this situation, the $T$ could be incremented. However, when the gateway receives few MRA packets from its neighbors, it must decrease the $T$ to ensure that nodes keep a valid route to the gateway when they require to be connected to internet.

In [39] Rosenschon et al. proposed a proactive gateway discovery scheme which makes use of hello messages to connect the MANET node to the internet. The ad hoc routing protocol such as AODV uses HELLO messages for neighborhood management. The gateway will send two types of packets periodically which are advertisements and HELLO messages. Here, every node sends HELLO messages periodically with a time to live (TTL) of 1 . The idea of this gateway discovery algorithm is that if a gateway uses HELLO packets for neighborhood discovery it does not need to send advertisements with a TTL of one additional to the HELLO messages. The advertisements can then be neglected and they may be substituted by special HELLO messages. Therefore, a flag was introduced to indicate that a special HELLO message was initiated by a gateway node and not a normal node. This flag was called the I-flag and thus, the modified HELLO messages are called HELLO-I messages. Since the HELLO messages were derived from RREPs there are empty fields in the header that can be used for the additional purpose for this kind of gateway discovery.

In this section we describe an adaptive gateway discovery mechanism proposed by Pedro M. Ruiz et al.[40] being that is able to dynamically change its proactiveness or reactiveness and can reduce the overhead of the gateway discovery. Here we describe a new adaptive gateway discovery approach based on the dynamic adjustment of the TTL of GWADV messages. In this approach the TTL of the GWADV messages is used as the parameter to adjust depending on the network conditions. The higher the TTL value, the higher the overhead due to the periodic advertisement and the lower the overhead associated to the reactive discovery of the Internet gateways. That is, the higher the TTL the higher the proactiveness of the approach. When TTL is NIL then it corresponds to a totally reactive approach. While, when TTL is equal to NETWORK DIAMETER it corresponds to a completely proactive scheme.

Md. Asif lqbal et al. [41] has proposed a hybrid gateway discovery scheme for internet gateway discovery. When a mobile node in the MANET wants to access the Internet, then it has to find a gateway. So, mobile node in this gateway discovery scheme looks in its routing table to find a default route i.e. a route to a gateway. If the mobile node finds a default route, it uses the route to send packets to the gateway i.e. to the Internet. However, if the mobile node does not find a route to a gateway in its routing table, it starts a gateway discovery process by broadcasting a gateway discovery 
(GWDSC) message in the MANET. While broadcasting the GWDSC message, the requesting mobile node sets an initial time to live (TTL) value for the message and starts a timer to wait for the reception of the gateway advertisement message from the gateways. When an intermediate node receives the GWDSC message it creates a reverse route entry for the requesting mobile node in its routing table and forwards the GWDSC message to its neighbors. In this way, a GWDSC message reaches one or more internet gateways in the network. The Gateway broadcasts a GWADV message when it receives the GWDSC message. The TTL value of the GWADV message is set equal to the distance of the gateway from the requesting mobile node.

Robert Brannstrom et al. [42] proposed a proactive gateway discovery scheme that is used to connect multi hop ad hoc networks with the internet. This approach reduces the delay in the gateway discovery process. As the advertisements may arrive to a mobile host through multiple paths, it is important to keep track of the best path to each gateway. Here the Running Variance Metric (RVM) and Relative Network Load (RNL) are used as performance metrics to classify the traffic load of gateways in wireless access networks. RVM and RNL can be efficiently used for infrastructure networks and ad hoc networks. In this scheme the Mobile IP is extended to enable mobile nodes to support multiple care of addresses simultaneously. The extension improves the network connectivity by enabling the mobile host, the home agent and correspondent hosts to evaluate and select the best connection. This extension is to Mobile-IP is called as multi-homed IP.

Sun et al.[43] has proposed the integration of the Ad Hoc On-Demand Distance Vector (AODV) routing protocol and Mobile IP. It gives a technique for activating nodes within an ad $\mathrm{Hoc}$ network to acquire internet connectivity when one or more nodes is in direct transmission range of a foreign agent or an Internet Gateway Router. In this approach, an Ad Hoc network is connected to a foreign agent, which exhibits the similar working as an Internet gateway (IGW). Internet Gateway assigns a global prefix for the Ad Hoc network, which makes it possible for mobile nodes in Ad Hoc network to communicate with Internet. In integrating MANET and INTERNET AODV is used for route discovery and maintenance within MANET, while Mobile IP gives a way for mobile nodes to get care-of addresses.

Hamidian et al. [44] proposed an approach which provides internet connectivity to Ad Hoc networks by modifying the AODV routing protocol. An "I" flag is added as an extension to AODV, RREQ and RREP to locate the fixed node. If after one network-wide search without receiving any corresponding route replies, the mobile node assumes that the destination is a fixed node, which is located in the internet and thus delivers the packets through a gateway. All the three methods of gateway discovery for a mobile node to access the internet are based on the number of physical hops to gateway as the metric for the gateway selection.

Hossam El-Moshrify et al. [45] proposed a solution in which mobile nodes can access the internet via a stationary gateway node or access point. The impact of the mobile terminals speed and the number of gateways on the network performance are compared in this approach. In this proposal the mobile node uses no load balancing approach to efficiently discover an internet gateway.

C. Jelger et al.[46] proposed a proactive gateway discovery approach in which internet gateways periodically advertise their presence by flooding information (GW_INFO) messages. This proposal uses a restricted flooding scheme, to limit the overhead of the proactive gateway discovery. The prefix continuity ensures that every node shares the same prefix and each gateway only receives IPv6 data packets belonging to its prefix. A mobile node chooses one of the GW_INFO messages according to some metrics. Then the node configures an IPv6 address based on the advertised prefix and sends only the GW_INFO message including the selected prefix. However, if the approach is unified with a reactive routing protocol, then a node in the network must discover a route otherwise it causes a break of the connection because of the property of the reactive routing protocol. It uses a stateless auto-configuration mechanism, which is based on network prefixes advertised by gateways. The nodes concatenate interface identifier to one of those prefixes to generate the IP address. A mobile node selects the optimal route towards the gateway using one of the metrics such as distance, stability, or delay from all the gateway information messages received.

Bin et al. [47] proposed an adaptive gateway discovery scheme that can dynamically adjust the TTL value of GWADV messages. This protocol provides internet access to MANET mobile nodes using mobile IP .The protocol uses foreign agents to track and forward packets to and from mobile nodes. Foreign agent periodically calculates the average hops by RREQ_I message or registration request sent by mobile nodes requesting internet connectivity. So the transmission range of GWADV can be adjusted dynamically according to real time applications demand.

In this section we describe an adaptive gateway discovery protocol proposed by Alicia Trivino Cabrera et al. [48] The aim of this proposal is to adapt the interval of emission of MRA messages to the mobility and traffic conditions of the mobile ad hoc network. So lower overhead is obtained while the losses do not increase. This scheme is based on the number of Modified Router Solicitation (MRS) messages generated by the mobile nodes in an interval of time called the MRS_COUNT_INTERVAL. The number of received MRS messages indicates the mobility and the necessity of updating the routes to the Internet. In this scheme, they observed the expected behavior of mobile nodes when the mobile nodes send the MRS messages to predict how many requests are expected to be received by the Internet Gateway in the next interval. This decision is taken based on the information about how the network is behaving at the present time and how it has behaved in past. 
Bok-Nyong Park et al. [49] proposed an adaptive gateway discovery approach for ubiquitous connectivity of ad hoc network with internet. This approach improves the load-balancing feature. After the routes are discovered to gateways, ad hoc mobile nodes should be able to select one Internet gateway providing the best internet connection. In the Internet gateway selection, this approach uses method to distribute data packets into different gateways while keeping low offered load.

Jonsson et al. [50] proposed a method, called MIPMANET based on AODV. It provides internet access by using tunneling and Mobile IP with foreign agent care-of addresses. Mobile nodes that want internet access register with a foreign agent and tunnel all packets destined for the Internet to the registered foreign agent. The packets destined for the internet are tunneled to the foreign agents, which in turn forward the packets to the destination in the internet. The hosts that do not want to access internet see the Ad Hoc network as a standalone network. The tunneling approach also enables MIPMANET to include the default route concept into on-demand routing. The Ad Hoc on demand distance vector routing protocol AODV is used within the mobile Ad Hoc network and delivers packets between mobile nodes and foreign agents. MIPMANET allows a visiting node to switch from its current foreign agent to a new one, a phenomenon known as handoff, only if it is at least two hops closer to the new one. It utilizes a new algorithm, called MIPMANET Cell Switching (MMCS), to determine when mobile nodes in the Ad Hoc network should register with a new foreign agent. In this solution, it is assumed that a mobile node that wants access to inernet has been assigned a home address that is valid on the Internet.

Ratanchandani et al. [51] proposed a hybrid gateway discovery approach to discover gateways that limits the effects of broadcast overhead. In this approach AODV and two Mobile IP foreign agents are used to interconnect MANET and the Internet. However, the TTL of the foreign agent's advertisements is limited to only a few hops. Thus, only mobile nodes that are close to one of the foreign agents receive the agent advertisements. Nodes that are further away have to solicit advertisements reactively. Intermediate nodes are allowed to reply on a solicitation with agent advertisements and to eavesdrop and cache agent advertisement information that is sent by unicast to the requesting mobile node. The performance of this approach depends on the Time-To-Live (TTL) value, which is set for a particular scenario and network condition under considerations. In order to switch between foreign agents, the MIPMANET Cell Switching algorithm is used.

Ghassemian et al. [52] proposed an approach in which the scalability of both proactive and reactive is compared with respect to the number of Internet Gateways. The fixed access network together with the Ad Hoc network creates a multi hop access network. The hybrid Internet gateway discovery approach is also compared that shows the average packet delay and the packet delivery ratio. This approach is beneficial because the packet delivery ratio is higher and the signaling overhead is also lesser for more number of gateways.

In [18], Ammari et al. proposed a mobile gateway based on three-layer approach using both Mobile IP protocol and DSDV Ad Hoc routing protocol. The first layer contains Mobile IP foreign agents, the second layer includes mobile gateways and mobile internet nodes, which are one-hop away from Mobile IP foreign agents; the third layer has all MANET nodes and visiting mobile internet nodes that are at least one-hop away from mobile gateways. The second layer is to provide internet connectivity to MANET nodes and, thus to help establish interaction between MANET nodes and the Internet. Mobile gateways are powerful MANET nodes and are designed in a way to use both Mobile IP protocol when they communicate with the Internet. The DSDV protocol is used for routing within the MANET. The integration framework considers using some border MANET nodes to connect the rest of MANET nodes to the Internet. These MANET nodes are referred as mobile gateways.

\section{COMPARISON AMONG EXISTING INTEGRATION APPROACHES}

In this section we present a comparative analysis of various protocols discussed above.

Table1: Comparison and Correlation among existing proposals

\begin{tabular}{|l|l|l|l|l|l|l|l|l|}
\hline $\begin{array}{l}\text { Proposed } \\
\text { Protocol }\end{array}$ & $\begin{array}{l}\text { Gateway } \\
\text { Discovery } \\
\text { Approach }\end{array}$ & $\begin{array}{l}\text { Mobil } \\
\text { e IP } \\
\text { Supp } \\
\text { ort }\end{array}$ & $\begin{array}{l}\text { Ad-Hoc } \\
\text { Routing } \\
\text { Protocol }\end{array}$ & $\begin{array}{l}\text { Multiple } \\
\text { Gateway } \\
\text { Support }\end{array}$ & $\begin{array}{l}\text { Stateful/ } \\
\text { Stateless }\end{array}$ & $\begin{array}{l}\text { Duplicate } \\
\text { Address } \\
\text { Detection }\end{array}$ & $\begin{array}{l}\text { Limited } \\
\text { Flooding }\end{array}$ & $\begin{array}{l}\text { Load } \\
\text { Balancing }\end{array}$ \\
\hline Khan et. al.[8] & Proactive & YES & DSDV & YES & Stateless & YES & NO & YES \\
\hline $\begin{array}{l}\text { K. palani et. } \\
\text { al[17] }\end{array}$ & Adaptive & YES & AODV & NO & Stateless & YES & YES & YES \\
\hline Khan et. al[6] & Proactive & YES & DSDV & YES & Stateless & YES & NO & YES \\
\hline Sandhu et. al[10] & Reactive & YES & AODV+ & YES & N/A & YES & YES & N/A \\
\hline Chaba et. al.[11] & Reactive & YES & DYMO & YES & Stateful & N/A & YES & NO \\
\hline Bouk. et. al[14] & Hybrid & YES & $\begin{array}{l}\text { DSR } \\
\text {,DSDV }\end{array}$ & NO & Stateless & YES & NO & YES \\
\hline Lee et. al[53] & Hybrid & YES & DSR & YES & Stateless & YES & NO & N/A \\
\hline
\end{tabular}




\begin{tabular}{|c|c|c|c|c|c|c|c|c|}
\hline Zhuang et.al[15] & Hybrid & YES & AODV & YES & $\mathrm{N} / \mathrm{A}$ & YES & NO & YES \\
\hline $\begin{array}{l}\text { Wakikawa } \\
\text { et.al[20] }\end{array}$ & $\begin{array}{l}\text { Proactive } \\
\text {,Reactive }\end{array}$ & IPv6 & Generic & YES & Stateless & YES & $\mathrm{NO}$ & $\mathrm{NO}$ \\
\hline $\begin{array}{l}\text { Domingo et. } \\
\text { al.[16] }\end{array}$ & Adaptive & YES & $\begin{array}{l}\text { AODV,D } \\
\text { SDV }\end{array}$ & $\mathrm{NO}$ & Stateless & YES & $\mathrm{NO}$ & YES \\
\hline Broch. Et. al[19] & Reactive & YES & DSR & $\mathrm{NO}$ & Stateless & YES & YES & YES \\
\hline $\begin{array}{l}\text { Ammari et. } \\
\text { al.[18] }\end{array}$ & Reactive & YES & DSDV & YES & Stateless & $\mathrm{NO}$ & YES & YES \\
\hline $\begin{array}{l}\text { F.D Trujillo et. } \\
\text { al.[38] }\end{array}$ & Adaptive & YES & DSDV & YES & Stateless & YES & $\mathrm{NO}$ & YES \\
\hline $\begin{array}{l}\text { Rosenchon et. } \\
\text { al.[39] }\end{array}$ & Proactive & $\mathrm{N} / \mathrm{A}$ & AODV & YES & Stateless & $\mathrm{NO}$ & NO & NO \\
\hline Ruiz. et. al.[40] & Adaptive & YES & DSDV & $\mathrm{Y}$ & $\mathrm{N}$ & YES & $\mathrm{NO}$ & YES \\
\hline lqbal et. al.[41] & Hybrid & $\mathrm{NO}$ & $\begin{array}{l}\text { DSR } \\
\text {,DSDV }\end{array}$ & $\mathrm{NO}$ & Sta & & $\mathrm{NO}$ & YES \\
\hline $\begin{array}{l}\text { Brannstrom et. } \\
\text { al.[42] }\end{array}$ & Proactive & YES & DSDV & & ess & $\overline{\mathrm{NO}}$ & $\mathrm{NO}$ & $\mathrm{NO}$ \\
\hline Sun et. al.[43] & $\begin{array}{l}\text { Proactive, } \\
\text { Reactive }\end{array}$ & $\overline{\text { YES }}$ & AODV & YE & Sta & $\overline{\text { YES }}$ & NO & YES \\
\hline $\begin{array}{l}\text { Hamidian et. } \\
\text { al.[44] }\end{array}$ & $\begin{array}{l}\text { Proactive, } \\
\text { Hybrid }\end{array}$ & $\mathrm{NO}$ & $\mathrm{AOI}$ & & $\overline{\mathrm{N}}$ & & YES & YES \\
\hline $\begin{array}{l}\text { Moshrify et. } \\
\text { al.[45] }\end{array}$ & $\begin{array}{l}\text { Proactive, } \\
\text { Reactive, } \\
\text { Hybrid }\end{array}$ & $\mathrm{NO}$ & $\overline{A O D V}$ & $\bar{Y}$ & $\bar{N} / \mathrm{A}$ & & YES & YES \\
\hline Jelger et. al[46] & Proactive & $\mathrm{N} / \mathrm{A}$ & $\mathrm{N} / \mathrm{A}$ & $\mathrm{YE}$ & Stateless & $\mathrm{YE}$ & YES & $\mathrm{NO}$ \\
\hline Bin et.[47] & Adaptive & YES & AODV & YES & $\bar{N} / \mathrm{A}$ & $\mathrm{NO}$ & YES & YES \\
\hline $\begin{array}{l}\text { Carbera et. } \\
\text { al.[48] }\end{array}$ & Adaptive & YES & DSDV & YES & Stateless & YES & $\mathrm{NO}$ & YES \\
\hline Park at. al.[49] & Adaptive & YES & $\begin{array}{l}\text { DSR,DS } \\
\text { DV }\end{array}$ & $\mathrm{NO}$ & $\mathrm{N} / \mathrm{A}$ & YES & NO & YES \\
\hline $\begin{array}{l}\text { Jonsson et. } \\
\text { al.[50] }\end{array}$ & $\begin{array}{l}\text { Proactive, } \\
\text { Reactive }\end{array}$ & YES & AODV & YES & Stateless & $\mathrm{NO}$ & YES & YES \\
\hline $\begin{array}{l}\text { Ratanchandani } \\
\text { et. al.[51] }\end{array}$ & Hybrid & YE & AODV & YES & Stateless & YES & $\mathrm{NO}$ & YES \\
\hline $\begin{array}{l}\text { Ghassemian et. } \\
\text { al.[52] }\end{array}$ & $\begin{array}{l}\text { Proactive, } \\
\text { Reactive }\end{array}$ & $\mathrm{N} / \mathrm{A}$ & AODV & YES & Stateless & $\mathrm{NO}$ & YES & YES \\
\hline
\end{tabular}

\section{CONCLUSION AND FUTURE SCOPE}

The aim of gateway discovery is to provide the mobile nodes connectivity to the internet. Various protocols have been proposed for this purpose. Each of them tries to improve the efficiency of the internet access through the gateway node. The protocol which should be chosen for gateway discovery should improve the packet delivery ratio and should minimize the latency of data transmission from internet to mobile ad hoc networks and vice-versa. The most popular gateway discovery protocol which is being used now a days is the adaptive gateway discovery protocol. In near future various enhancements to this approach will arrive. We are working to improve the efficiency of gateway discovery process to improve the network throughput and reduce congestion.

\section{LATEST RESEARCH TRENDS}

Gateway discovery is a new and emerging area in the field of mobile ad hoc network. Various new protocols on gateway discovery are being proposed in every shorter span of time. Here we give a list of technologies which are popular now a days. 
D Optimization Of Gateway Discovery Process in mobile ad hoc networks.

$>$ Gateway Selection for Hybrid MANETs.

$>$ Location-Aided Gateway Advertisement and Discovery Protocol for Vehicular ad hoc networks

$>$ Dynamic Clustering based adaptive gateway management for vehicular ad hoc networks.

> Gateway Discovery Protocols based on multiple QOS Path Parameters between Mobile Node and Gateway Node.

$>$ Improvement for working outside the MANET through extension of MANET Routing Protocol.

$>$ Extension of Gateway forwarding strategies used for MANET.

$>$ Adaptive Distributed Gateway Discovery in Hybrid Wireless Networks.

\section{REFERENCES}

[1] Elizabeth M. Royer and Chai- Keong Toh, "A review of current routing protocols for ad hoc mobile wireless networks", Technical report, University of California and Georgia Institute of Technology, USA, 1999.

[2] R.Kumar, "Performance Evaluation of Gateway Discovery Approaches in the Integrated Mobile Ad Hoc Network (MANET)-Internet Scenario", International Journal of Computer Technology and Electronics Engineering (IJCTEE) Volume 2, Issue 3, June 2012.

[3] Sajendra Kumar, Sachin Chaudhary, "Performance Analysis of Three Gateways Discovery Approaches in AODV Routing Protocol for Connectivity with Wired Network", IJCSI Vol. 3, Jan. - March 2012.

[4] Harpreet Kaur Sandhu and Roopali Garg , "performance evaluation of gateway discovery routing protocols in manets ", International Journal of Computer Science, Engineering and Applications (IJCSEA), June 2012.

[5] Khaleel Ur Rahman Khan, Prof. A Venugopal Reddy, Rafi U Zaman,"An Efficient Integrated Routing Protocol for interconnecting Mobile Ad Hoc Network and the Internet", International Journal of Computer and Electrical Engineering, Vol. 1, No. 1, April 2009,1793-8198

[6] Khaleel Ur Rahman Khan, Rafi U Zaman, A. Venugopal Reddy," The Performance of the Extended DSDV (eDSDV) MANET Routing Protocol and its Suitability in Integrated Internet-MANET"

[7] Perkins, C.E. and Bhagwat, P. (1994) "Highly Dynamic Destination Sequence-Vector Routing (DSDV) for Mobile Computers", Computer Communication Review,24(4), pp 234-244.

[8] Khaleel Ur Rahman Khan, Rafi U Zaman, A Venugopal Reddy, "A Bi-Directional Connectivity Framework for Mobile Ad Hoc Network and the Internet".

[9] M.Geetha, Dr. R. Umarani, "Performance Comparison and Analysis of AODV and DSDV Gateway Discovery Protocol in MANET", International Journal of Engineering Science and Technology, Vol. 2(11), 2010, 6521-6531

[10] Harpreet Kaur Sandhu and Roopali Garg," performance evaluation of gateway discovery routing protocols in manets", International Journal of Computer Science, Engineering and Applications (IJCSEA) Vol.2, No.3, June 2012

[11] Yogesh Chaba, R. B. Patel, and Rajesh Gargi," Efficient Multipath DYMO Routing Protocol with Gateway Selection for Hybrid MANETs", International Journal of Computer Theory and Engineering, Vol. 4, No. 4, August 2012.

[12] M. Nacher, C. T. Calafate, and P. Manzoni, "Multi-path extensions to the DYMO routing protocol", IEEE 2008.

[13] M.Geetha,R.Umarani, R.Kiruthika,"A Comparative Study of Gateway Discovery Protocol in MANET", International Journal of Computer Applications (0975 - 8887), Volume 11-No.2, December 2010.

[14] Safdar Hussain Bouk, Iwao Sasase, Syed Hassan Ahmed, and Nadeem Javaid, " Gateway Discovery Algorithm Based on Multiple QoS Path Parameters Between Mobile Node and Gateway Node", journal of communications and networks, vol. 14, no. 4, august 2012.

[15] Lin Zhuang, Yuanan Liu, Kaiming Liu, Linbo Zhai, Ming Yang," A Hybrid Internet Gateway Discovery Scheme in Mobile Ad Hoc Networks", WASE International Conference on Information Engineering,2009

[16] Mari Carmen Domingo," An Adaptive Gateway Discovery Algorithm to support QoS when providing Internet Access to Mobile Ad Hoc Networks", cdomingo@mat.upc.es

[17] K.Palani, P.Ramamoorthy," QoS based Analysis of Proxied Adaptive Gateway Discovery Scheme for Mobile Ad hoc Networks", IJCSI International Journal of Computer Science Issues, Vol. 9, Issue 3, No 3, May 2012

[18] H. Ammari and H. El-Rewini, "Integration of Mobile Ad Hoc Networks and the Internet using Mobile Gateways,"Proceeding of the 4th International Workshop on Algorithms for Wireless, Mobile, Ad Hoc and Sensor Networks (WMAN04), Santa Fee, New Mexico, USA, April 26-30, 2004.

[19] J. Broch, D.A. Maltz, and D.B. Johnson, "Supporting Hierarchy and Heterogeneous Interfaces in Multi-Hop Wireless Ad Hoc Networks," in Proceedings of the IEEE International Symposium on Parallel Architectures, Algorithms, and Networks, Perth, Western Australia, pp. 370-375, June 1999.

[20] Wakikawa R., Malinen J., Perkins C., Nilsson A., "Global Connectivity for IPv6 Mobile Ad Hoc Networks" In IETF 505 | $\mathrm{P}$ a g e w w w. ijcton I in e.com 
Internet Draft 2003.

[21] Quan Le-Trung1, Paal E. Engelstad, "Providing Internet connectivity and mobility management for MANETs"

[22] Sajendra Kumar,Sachin Chaudhary, "Performance Analysis of Three Gateways Discovery Approaches in AODV Routing Protocol for Connectivity with Wired Network", IJCST Vol. 3, Issue 1, Jan. - March 2012

[23] Hossam El-Moshrify, M. A. Mangoud,"Gateway Discovery in Ad hoc On-Demand Distance Vector (AODV) Routing for Internet Connectivity", National Radio Science Conference (Nrsc 2007) March 13-15, 2007

[24] Koushik Majumder, Dr. Sudhabindu Ray, "Implementation and Performance Evaluation of the Gateway Discovery Approaches in the Integrated MANET- Internet Scenario", International Journal on Computer Science and Engineering (IJCSE)

[25] Quan Le-Trung, Paal E. Engelstad, "Providing Internet Connectivity and Mobility management for mobile adhoc networks".

[26] Christophe Jelger,Thomas Noel,"Proactive Address auto-configuration and Prefix Continuity in IPv6 Hybrid Ad Hoc Network"

[27] Majid Taghiloo, Mehdi Dehghan,"New Approach for Address Auto-Configuration in MANET Based on Virtual Address Space Mapping(VASM)"

[28] K. Weniger, M. Zitterbart, "Address Auto-configuration in Mobile Ad Hoc Networks: Current Approaches and Future Directions," ,IEEE Network Magazine Special issue on Ad Hoc Networking, July 2004.

[29] Tarek R Sheltami "'Gateway Selection Review in Ad hoc Networks”, journal of computers, vol. 1, no. 2, may 2006

[30] Ahmed Mustafa Mahmoud, Dr. Ben McCarthy, Dr. Christopher Edwards, "Gateway Selection in Mobile Ad-hoc Networks"

[31] D. Johnson, C. Perkins, J. Arkko, "Mobility Support in IPv6," IETF RFC 3775, June 2004.

[32] E. Belding-Royer, Y. Sun, and C. Perkins. Global connectivity for IPv4 mobile ad hoc networks, November 2001. IETF Internet Draft, draft-royer-manet-globalv4-00.txt, (work in progress)

[33] Erik Nordstrom, Per Gunningberg and Christian Tschudin," Gateway Forwarding Strategies for Ad hoc Networks", Department of Information Technology, Uppsala University, mail id- erikn/perg@it.uu.se

[34] Erik Nordstrom, Per Gunningberg, Christian Tschudin," Comparison of Forwarding Strategies in Internet Connected MANETs"

[35] Erik Nordstrom ,Per Gunningberg ,Christian Tschudin," Evaluating Gateway Forwarding in Ad hoc Networks", Department of Information Technology, Uppsala University

[36] Hongbo Zhou and Matt W. Mutka," IP Address Handoff in the MANET"

[37] Kun Zhu, Dusit Niyato, Ping Wang, Ekram Hossain, and Dong In Kim," Mobility and Handoff Management in Vehicular Networks: A Survey" wireless communications and mobile computing Wirel. Commun. Mob, (2009)

[38] F. D. Trujillo, A. Trivino, E. Casilari, A. Díaz- Estrella," An adaptive gateway discovery in hybrid MANETs"

[39] M. Rosenschon, T. Manz, J. Habermann, V. Rakocevic, "Gateway Discovery Algorithm for Ad-Hoc networks using HELLO Messages," International Workshop on Wireless Ad Hoc Networks IWWAN 2005, London, May 2005.

[40] Pedro M. Ruiz and Antonio F. Gomez-Skarmeta, "Enhanced Internet Connectivity for Hybrid Ad hoc Networks Through Adaptive Gateway Discovery", University of Murcia,Dept. Information and Communications Engineering.

[41] Shahid Md. Asif Iqbal and Md. Humayun Kabir," Hybrid scheme for discovering an selecting internet gateway in mobile ad hoc network", International Journal of Wireless \& Mobile Networks (IJWMN) Vol. 3, No. 4, August 2011

[42] Robert Brannstrom, Christer Ahlund, and Arkady Zaslavsky," Maintaining Gateway Connectivity in Multi-hop Ad hoc Networks"

[43] Y. Sun, E. M. Belding-Royer, and C. E. Perkins, "Internet Connectivity for Ad Hoc Mobile Networks," International Journal of Wireless Information Networks, Special Issue on Mobile Ad Hoc Networks (MANETs): Standards, Research, Application. 9(2), pp. 75-88, April 2002.

[44] A. Hamidian, U. Korner, and A. Nilsson, "A Study of Internet Connectivity for Mobile Ad Hoc Networks in NS2", Department of Communication Systems, Lund Institute of Technology, Lund University, January 2003.

[45] Hossam El-Moshrify, M. A. Mangoud, M.Rizk, "Gateway Discovery in Ad Hoc On-Demand Distance Vector (AODV) Routing for Internet Connectivity," 24th National Radio Science Conference (NRSC 2007), March 13-15, 2007,Faculty of Engineering, Alexandria University Alexandria 21544., Egypt.

[46] C. Jelger, T. Noel, A. Frey, "Gateway and Address Auto configuration for IPv6 Ad Hoc Networks," IETF internet- 
Draft, draft-jelger-manet-gateway-autoconf-v6-02.txt, April 2004

[47] S. Bin, S. Bingxin, L. Bo, H. Zhonggong, and Z. Li, "Adaptive Gateway Discovery Scheme for Connecting Mobile Ad Hoc Networks to the Internet," Proceedings of International Conference on Wireless Communications, Networking and Mobile Computing, vol. 2, pp. 795-799,2005.

[48] Alicia Trivino-Cabrera, Bernardo Ruiz-Villalobos, Eduardo Casilari," Adaptive Gateway Discovery in Hybrid MANETs", ASWN ,2007 - Applications and Services in Wireless Networks

[49] Bok-Nyong Park, Wonjun Lee, Choonhwa Lee, Jin Pyo Hong,and Joonmo Kim," LAID: Load-Adaptive Internet Gateway Discovery for Ubiquitous Wireless Internet Access Networks

[50] U. Jonsson, F. Alriksson, T. Larsson, P. Johansson, and G.M. Maquire, "MIPMANET: Mobile IP for Mobile Ad Hoc Networks,",Proceedings of IEEE/ACM Workshop on Mobile and Ad Hoc Networking and Computing (MobiHoc 2000), Boston, MA USA, pp. 75-80, August 1999.

[51] P. Ratanchandani, and R. Kravets, "A Hybrid Approach to Internet Connectivity for Mobile Ad Hoc Networks," in Proceedings of the IEEE WCNC 2003, New Orleans, USA, vol. 3, pp. 1522-1527, March 2003.

[52] M. Ghassemian, P. Hofmann, C. Prehofer, V. Friderikos and H. Aghvami, " Performance Analysis of Internet Gateway Discovery Protocols in Ad Hoc Networks," IEEE WCNC 2004, Atlanta, Georgia, USA.

[53] J. Lee, D. Kim, J. J. Garcia-Luna-Aceves, Y Choi, J Choi, and S. Nam, "Hybrid Gateway Advertisement Scheme for Connecting Mobile Ad Hoc Networks to the Internet, " in Proceedings of the 57th IEEE VTC2003, Jeju, Korea, vol. 1, pp. 191-195, 2003

\section{Author' Biography}

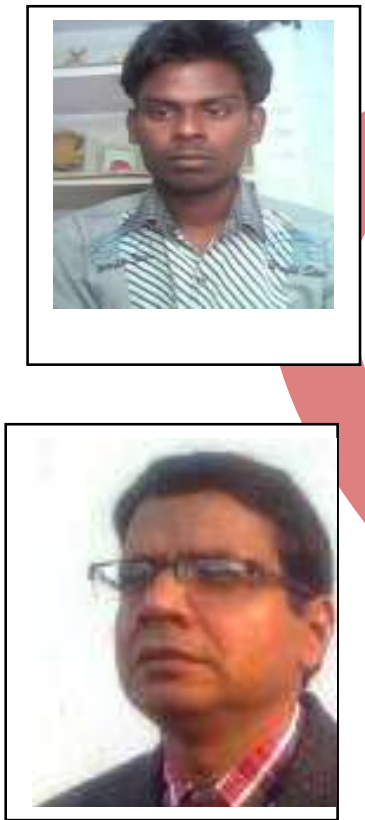

Deepak Kumar Patel is a student of M.Tech in department of Computer Science and Engineering in MMM. Engg. College Gorakhpur. He received his B. tech degree in CSE stream from S.R.M.S. College of engg. and technology,Bareilly.

Rakesh kumar is an associate professor in the department of Computer science and engineering from MMM. Engineering College Gorakhpur. He received his Phd degree in the dept. of electronics and computer engineering in june 2011 from IIT, Roorkee. He has specialization in Mobile adhoc routing. 